\title{
Современное состояние яблоневых сообществ северного хребта Жетысуского Алатау
}

\section{The current state of apple communities in the Zhetusu Alatau northern ridge}

\author{
Кердяшкин А. В., Шадманова Л. Ш., Говорухина С. А., Калиев Б. Ш. \\ Kerdyashkin A. V., Shadmanova L. Sh., Govorukhina S. A., Kaliev B. Sh. \\ Институт ботаники и фитоинтродукции КН МОН РК, г. Алматы, Казахстан, E-mail: atamo@таil.ru \\ Institute of Botany and Phytointroduction CS MES of RK, Almaty, Kazakhstan
}

\begin{abstract}
Peфepam. В статье приведены лесоводственные описания 17 яблоневых сообществ, произрастающих в Североджунгарской горной подпровинция Жетысуского Алатау в поясах: степном (13 сообществ) и мелколиственных лесов (4). Большинство из них произрастает на склонах Тополевской и Лепсинской межгорных котловин. Malus niedzwetzkyana произрастает в Жетысуском и Илейском Алатау, хотя в научной справочной литературе для этих мест она не указана. Рекомендуется привести этот вид для данных регионов в следующих изданиях этих книг. Malus sieversii и M. niedzwetzkyana занесены в Красную книгу Казахстана, их численность имеет тенденцию к сокращению, поэтому необходимо проводить лесоводственные мероприятия по их сохранению.
\end{abstract}

Ключевые слова. Жетысуский Алатау, лесоводственные описания, сообщества, яблоня Недзвецкого, яблоня Сиверса.

Summary. The paper presents the silvicultural information of 17 communities of Malus sieversii and M. niedzwetzkyana, growing in the North Dzungar mountain subprovince of Zhetysu Alatau: in the steppe (13 communities) and in smallleaved forests (4) altitudinal zones. Most of the apple communities were found on the slopes of the Topolevka and Lepsinsk intermountain valleys. Malus niedzwetzkyana grows in Zhetysu and Ile Alatau, although in the scientific reference books for these places they are not listed. It is recommended in the following editions of these books to indicate these species for these regions. Malus sieversii and M.niedzwetzkyana are listed in the Red Book of Kazakhstan. Their quantity tends to decrease, so it is necessary to carry out silvicultural activities to preserve them.

Key words. Communities, Nedzvetsky apple tree, silvicultural information, Sivers apple tree, Zhetysu Alatau.

Ценные плодовые леса из яблонь Сиверса (Malus sieversii (Ledeb.) M. Roem.) и Недзвецкого (Malus niedzwetzkyana Dieck ex Koehne), произрастающие в Жетысуском Алатау (Джунгарский Алатау), страдают из-за нерационального хозяйствования и антропогенного воздействия (рубки древостоя, перевыпаса скота, распашки земель, рекреационных нагрузок и пр.). Исследования в Жонгар-Алатауском государственном национальном природном парке (ГНПП) выявили неудовлетворительное состояние диких яблоневых лесов (Касенова, Кентбаева, 2017). По данным А. Д. Джангалиева (2007), в Джунгарском Алатау площадь плодовых лесов с 1960 по 2007 гг. сократилась на 28 \%: антропогенное воздействие привело к резкому сокращению яблони в ущельях Солдатское, Пихтовое и Черная речка. Основные факторы деградации лесов: ненадлежащее управление ресурсами, разрушение экосистем хозяйственной деятельностью, перепрививка дикой яблони культурными деревьями, вытеснение яблони из природных сообществ интродуцированными видами и пр. (Джангалиева, 2007). В этой связи необходимо проводить мониторинговые мероприятия, направленные на изучение современного состояния лесных сообществ, их антропогенной трансформации для дальнейшего рационального ведения хозяйства и их охраны.

В соответствии с дендрологическим районированием Казахстана территория исследований относятся к Джунгарскому дендрологическому району области распространения ели Шренка и сопутствующих видов (Ролдугин, Мальцев, 2011). Согласно ботанико-географическому районированию Казахстана Джунгарский Алатау относятся к Сахаро-Гобийской пустынной области, Ирано-Туранской 
подобласти, Джунгаро-Северотяньшаньской провинции, Южноджунгарской и Североджунгарской горным подпровинциям (Рачковская и др., 2003).

Закономерности распределения горной растительности связаны с высотной (вертикальной) зональностью. Североджунгарская горная подпровинция характеризуется Заилийско-Североджунгарским типом поясности. Растительность поясов и подпоясов (высота над ур. м.): пояс предгорных пустынь (600-800 м); степной пояс (800-1400 м) с подпоясами опустыненных (800-1000 м), настоящих (1000-1200 м) и луговых степей (1200-1400 м); пояс мелколиственных лесов (1400-1700 м), пояс темнохвойных лесов и лугов (1700-2300 м); пояс субальпинотипных лугов и стлаников (2300-2800 м); пояс криофитных (альпинотипных) лугов (2800-3300 м); субнивальный пояс (3300-3600 м) (Волкова, 2003).

Malus sieversii, M. niedzwetzkyana относятся к семейству Rosaceae. Malus sieversii - среднеазиатский, реликтовый, автотрофный и мезофильный вид лиственных лесов олигоцена, который обладает большим полиморфизмом и занимает широкий ареал произрастания. Malus niedzwetzkyana - небольшое дерево 5-8 м высотой с гладкими ветвями, без колючек, с буро-красной корой, молодые побеги и листья в период распускания имеют темно-пурпурный цвет, цветки красные, плоды фиолетово-темно-красные с розово-пурпуровой мякотью. Яблоня устойчива к вредителям и болезням, быстро растет, высоко ценится за декоративные качества (Мичурин, 1948).

Естественные яблоневые леса являются надежным исходным ботанико-географическим и селекционно-генетическим материалом для селекции и гибридизации культурных сортов, ценнейшим генофондом для использования в плодоводстве, озеленении и медицине. Культурные яблони на 46 \% генома произошли от Malus sieversii, на $21 \%$ - от яблони лесной и остальные - от иных видов (Реiх et al., 2018). Геном Malus sieversii обеспечивает значительный размер плодов и устойчивость сортов к болезням и вредителям.

В основу исследований положены данные экспедиционных выездов в северную часть Джунгарского Алатау. Гербарные образцы были определены посредством флористических сводок (Флора Казахстана, 1956-1966; Иллюстрированный определитель ..., 1969, Голоскоков, 1984, Черепанов, 1995). Для установления мест произрастания Malus niedzwetzkyana в Джунгарском Алатау были использованы результаты критического просмотра коллекций Гербария Института ботаники и фитоинтродукции (г. Алматы). Состояние растительного покрова определялось с помощью классических методов В. Н. Сукачева, С. В. Зонна (1961) и Б. А. Быкова (1978).

Исследования проводились на ключевых участках размером 200 м² (ОСТ 56-69-83; Голуб, 2011). Лесоводственные описания включали следующие характеристики: координаты, географическое положение, абсолютная высота, микро- и макрорельеф; описание древостоя (название сообщества, состав, происхождение, количество деревьев, густота, сомкнутость крон, полнота, бонитет, высота, возраст, диаметр деревьев, фенофаза, размер проекции крон, среднее расстояние между деревьями, состояние, жизненность по Сукачеву и Крафту, характер размещения); для подроста указывались: состав, количество, высота и характер размещения; для травяного покрова: проективное покрытие, задернованность, обилие по Друде, высота и фенофаза, размещение по Быкову, стадия антропогенной трансформации (Сукачев, Зонн, 1961; Юнатов, 1964; Быков, 1973; Анучин, 1982).

Для характеристики растительного покрова была использована "шкала жизненности" В. Н. Сукачева (Сукачев, Зонн, 1961): 1 - вид нормально развивается, достигает своих обычных размеров, проходит весь цикл своего развития, плодоносит; 2 - вид проходит все стадии своего развития, плодоносит, но не достигает своих нормальных размеров; 3 - вид вегетативно развивается, но не плодоносит; 4 - вид сильно угнетен, но не плодоносит.

Характер размещения видов определялся по шкале Б. А. Быкова (1973): un (единично во всем сообществе), gr (группой - единично, диффузно), mс (пятном - единично, слитно), ggr (группами), $\mathrm{mmc}$ (пятнами), df (диффузно), coal (слитно).

Распределение деревьев одной популяции по степени господства и жизненности определялось по шкале Э. Крафта (Быков, 1973): I - исключительно господствующие, выделяются над пологом древесных крон; II - господствующие, главная часть древесного полога; III - согосподствующие, входят в общий полог, но затененные; IV - вполне угнетенные, почти лишенные ветвей, отмирающие. 
Для оценки антропогенной трансформации растительности были выделены следующие стадии (Рачковская и др., 1999): фоновая (естественная или слабонарушенная) - имеется полный набор доминантных и сопутствующих видов; умеренная - сохраняется основной состав доминантных видов, но нарушается полнота флористического состава сообществ; средняя - значительно сокращается видовое разнообразие сообществ, сохраняются лишь устойчивые к выпасу виды; сильная - угнетение доминантного состава видов, выпадение из травостоя большинства сопутствующих видов и разрастание сорных видов; очень сильная - замена доминантных, многолетних растений сорными однолетниками или не поедаемыми скотом многолетниками, появление участков, лишенных растительности.

Полевые исследования проводились с мая по август 2018 г. на 17 ключевых участках на северном макросклоне Джунгарского Алатау. В мае исследования проведены на 7 ключевых участках в границах Жонгар-Алатауского ГНПП: вблизи п. Екиаша и Тополевка, Никонова грива, склон г. Кокжоты, приток р. Теректы (1 участок); вблизи п. Лепсинск, долина р. Лепсы, Черновский инспекторский участок $(2,3,4)$; вблизи п. Лепсинск, перевал «Коктобе», г. Жунжурек, приток р. Лепсы $(5,6)$; возле п. Кокжар, долина р. Тентек (7). В августе 2018 г. исследования проведены за пределами Жонгар-Алатауского ГНПП на 5 ключевых участках: вблизи п. Сапак, г. Сарымсакты, в долине р. Тентек (8 участок) и вблизи п. Токжайлау, г. Кайкан, приток р. Орта Тентек $(9,10,11,12)$.

Исследования проведены также в трех селекционно-генетических резерватах: «Мушабай», в одноименном водоразделе р. Солдатская и р. Пихтовая (13 и 14 участки); «Пихтовая щель», в водоразделе «Мушабай», на левобережье р. Теректы, на землях Саркандского лесхоза (15); «Крутое», южнее п. Жунжурек, на правобережье р. Лепсы, участок охватывает два водораздела с их направленными друг к другу склонами и днища отщелка (16 и 17).

Лесоводственные описания яблоневых сообществ приведены в порядке возрастания абсолютной высоты их произрастания.

Участок 8. Разнотравно-злаково-яблоневое сообщество, 959 м над ур. м. Состав 10Я (Malus sieversii) - 16 экз. Сомкнутость крон 0,8. Размер крон 4 х 5 м. Среднее расстояние между деревьями 3-5 м. Средний возраст 15-20 лет. Средняя высота 7 м. Средний диаметр 19 см. Бонитеты V, Va, Vб. Жизненность по Сукачеву 3 балла. Возобновление хорошее (75 экз. подроста).

Травяной покров состоит из следующих злаков: Poa pratensis (доминант), Brachypodium pinnatum (доминант), Urtica dioica, Impatiens noli-tangere, Filipendula ulmaria, Arctium lappa, Euphorbia lamprocarpa, Centaurea pseudosquarrosa, Humulus lupulus (лиана). Проективное покрытие 50 \%. Задернованность -10 \%. Высота 0,3-1 м. Жизненность по Сукачеву- 1 балл. Размещение - диффузно и группами. Преобладают виды из семейств Poaceae (3 вида), Rosaceae (3) и Asteraceae (2). Антропогенная трансформация сильная, наблюдается выпас скота.

Участок 2. Злаково-разнотравное-тополево-яблоневое сообщество, 1118 м над ур. м. Состоит из Malus sieversii и Populus nigra. Подлесок состоит из Padus avium, Prunus stepposa. Размещение диффузно.

Травяной покров состоит из Dactylis glomerata (доминант), Aconitum sp. (доминант), Pulmonaria mollis, Heracleum dissectum, Ranunculus repens, Arctium lappa, Conium maculatum, Ligularia sp., Corydalis ledebouriana. Проективное покрытие $-80 \%$. Задернованность $-20 \%$. Высота 0,1-0,25 м. Жизненность по Сукачеву- 1 балл. Размещение - диффузно и группами. Антропогенная трансформация фоновая.

Участок 12. Злаково-разнотравно-боярышниково-осиново-яблоневое сообщество, 1118 м над ур. м. Состав 4Я4Ос2Б: 4 Malus sieversii, 4 Populus tremula и 2 Crataegus songarica. Сомкнутость крон 0,6. Размер крон -4 х 5 м. Среднее расстояние между деревьями - 5 м. Средний возраст - 30-40 лет. Средняя высота - 5-10 м. Жизненность по Сукачеву - 1 балл (Populus tremula) и 2 балла (Crataegus songarica и Malus sieversii). Подлесок состоит из Rosa platyacantha, Lonicera microphylla, Prunus stepposa, Spiraea hypericifolia, Rubus caesius. Растения плодоносят. Высота - 2 м. Размещение - пятнами.

Травяной покров состоит из злаков: Poa pratensis (доминант), Bromus squarrosus (доминант) и Elytrigia repens (доминант); из разнотравья: Euphorbia lamprocarpa, Solidago virgaurea, Berteroa incana, Thalictrum minus, Salvia deserta. Проективное покрытие- 60 \%. Задернованность- 20 \%. Высота -до 1 
м. Жизненность по Сукачеву - 1 балл. Размещение - пятнами. Преобладают виды из Rosaceae (6 видов), Poaceae (3) и Asteraceae (1). Антропогенная трансформация средняя.

Участок 15. Боярышниково-яблоневое сообщество, 1138 м над ур. м. Состав 8Я2Б: Malus sieversii (15 экз.) и Crataegus songarica. Сомкнутость крон -0,6. Размер крон - 5 х 5 м. Среднее расстояние между деревьями - 3-4 м. Средний возраст - 75 лет. Средняя высота - 6-8 м. Средний диаметр 41 см. Бонитеты V, Va, Vб. Полнота до 0,8. Густота - 26-50 \%. Виды плодоносят. Жизненность по Сукачеву - 2 балла. Жизненность по Крафту - II балла. Состояние удовлетворительное. Размещение пятнами, группами и диффузно. Подлесок состоит из Rosa alberti, Berberis sphaerocarpa, Rubus idaeus, Rubus caesius.

Травяной покров состоит из разнотравья: Origanum vulgare (цветет), Chamaenerion angustifolium, Hypericum perforatum, Poa pratensis, Inula britannica. Проективное покрытие - 70 \%. Высота 0,5-1,5 м. Жизненность по Сукачеву - 1 балл. Размещение - пятнами, группами и диффузно. Преобладают виды из Rosaceae (4 вида). Антропогенная трансформация средняя.

Участок 14. Боярышниково-осиново-кленово-яблоневое сообщество, 1140 м над ур. м. Состав: Malus sieversii (14 экз.), Acer semenovii, Populus tremula, Crataegus songarica. Сомкнутость крон -0,6. Размер крон -5 х 5 м. Среднее расстояние между деревьями -3-5 м. Средний возраст - 60-80 лет. Средняя высота -12 м. Густота - 20-50 \%. Бонитет V. Состояние удовлетворительное. Жизненность по Сукачеву -2 балла. Жизненность по Крафту -II балла. Подлесок состоит из Rhamnus cathartica. Размещение - группами.

Травяной покров состоит из разнотравья: Urtica dioica, Euphorbia lamprocarpa, Dryopteris filixmas, Chelidonium majus, Cuscuta campestris, Humulus lupulus (лиана). Проективное покрытие -70 \%. Высота 0,5-1 м. Жизненность по Сукачеву -1 балл. Размещение - группами. Преобладают виды из Rosaceae (2 вида). Антропогенная трансформация средняя.

Участок 13. Боярышниково-осиново-кленово-яблоневое сообщество, 1145 м над ур.м. Древостой состоит из Malus sieversii (20 экз.), Acer semenovii, Populus tremula, Crataegus songarica. Сомкнутость крон- 0,5 . Размер крон -5 х 5 м. Среднее расстояние между деревьями $-3-5$ м. Средний возраст50 лет. Средняя высота- 6-8 м. Густота $-30-50 \%$. Бонитет V, Va, Vб. Высота до 2 м. Состояние удовлетворительное. Жизненность по Сукачеву- 2 балла. Жизненность по Крафту- II балла. В подлеске Rhamnus cathartica. Размещение - группами.

Травяной покров состоит из разнотравья: Urtica dioica, Euphorbia lamprocarpa, Dryopteris filixmas, Chelidonium majus, Cuscuta campestris, Humulus lupulus (лиана). Проективное покрытие -70 \%. Высота $-0,5-1$ м. Жизненность по Сукачева -1 балл. Размещение - диффузно и группами. Преобладают виды из Rosaceae (3 вида). Антропогенная трансформация средняя.

Участок 9. Злаково-кустарниково-яблоневое сообщество, 1243 м над ур. м. Состав 10Я: Malus sieversii (5 экз.). Сомкнутость крон - 0,7-0,8. Размер крон - 4 х 4 м. Среднее расстояние между деревьями $-2,5$ м. Средний возраст - 40 лет. Средняя высота древостоя -3 м. Средний диаметр- $10-30$ см. Бонитеты V, Va, Vб. Жизненность по Сукачеву - 2 балла. Malus sieversii (плохо размножается, 1 экз. подроста). Состав подлеска 7СЗБ+Ш: Spiraea hypericifolia, Berberis sphaerocarpa и Rosa platyacantha. Растения плодоносят. Высота - 0,5-2 м. Размещение - пятнами.

Травяной покров состоит из злаков: Poa bulbosa (доминант), Bromus japonicus и Alopecurus pratensis; из разнотравья: Sedum hybridum, Hypericum scabrum, Ferula sp. и Origanum vulgare. Проективное покрытие $-70-80 \%$. Задернованность - 50-60 \%. Высота - 0,3-1 м. Жизненность по Сукачеву 2 балла. Размещение - диффузно и группами. Преобладают виды их Poaceae (3 вида) и Rosaceae (4). Антропогенная трансформация фоновая.

Участок 3. Рябчиково-злаково-яблоневое сообщество с жимолостью, 1274 м над ур. м. Состав древостоя: Malus sieversii (60 \%) и M. niedzwetzkyana (40 \%). Подлесок состоит из Lonicera microphylla. Размещение - диффузно и группами. 
Травяной покров состоит из разнотравья: Dactylis glomerata (доминант), Fritillaria pallidiflora (краснокнижный, доминант), Arctium lappa, Hedysarum neglectum, Pulmonaria mollis, Humulus lupulus (лиана). Проективное покрытие - 70 \%. Задернованность - 20 \%. Высота - до 0,4 м. Жизненность по Сукачеву - 1 балл. Размещение - диффузно и группами. Антропогенная трансформация фоновая.

Участок 4. Разнотравно-злаково-яблонево-еловое сообщество, 1283 м над ур.м. Состав: Picea schrenkiana и Malus sieversii. В подлеске - Rubus idaeus. Травяной покров состоит из злаков: Dactylis glomerata (доминант) и Brachypodium pinnatum (доминант); из разнотравья: Pulmonaria mollis, Hedysarum neglectum, Corydalis ledebouriana, Arctium lappa, Urtica dioica, Anemone caerulea, Taraxacum officinale, Ranunculus repens, Humulus lupulus (лиана). Проективное покрытие - 60 \%. Задернованность30 \%. Высота до 0,3 м. Жизненность по Сукачеву 1 балл. Размещение видов - диффузно и группами. Антропогенная трансформация - фоновая.

Участок 10. Разнотравно-шиповниково-яблоневое сообщество, 1319 м над ур. м. Состав 10Я: Malus sieversii. Сомкнутость крон 0,7-0,8. Размер крон 5 х 7 м. Среднее расстояние между деревьями 2,5 м. Средний возраст 40 лет. Средняя высота 3-5 м. Средний диаметр 31 см. Бонитеты V, Va, Vб. Жизненность по Сукачеву 3 балла. Возобновление неудовлетворительное (1 экз.). Подлесок состоит из Rosa platyacantha, Lonicera microphylla, Juniperus sibirica. Растения плодоносят. Высота до 1,5 м. Размещение - группами и пятнами.

Травяной покров состоит из разнотравья: Dactylis glomerata (доминант), Urtica dioica (доминант), Impatiens noli-tangere, Filipendula ulmaria, Glycyrrhiza uralensis, Arctium leiospermum, Artemisia vulgaris, A. dracunculus, Euphorbia lamprocarpa, Convolvulus arvensis, Chondrilla juncea, Solidago virgaurea, Bupleurum exaltatum, Goniolimon sp., Hypericum scabrum. Проективное покрытие - 50 \%. Задернованность -20 \%. Высота до 1,6 м. Жизненность по Сукачеву 1 балл. Размещение - пятнами и группами. Преобладают виды из Asteraceae (7 видов) и Rosaceae (2). Антропогенная трансформация - фоновая.

Участок 7. Злаково-яблоневое сообщество, 1322 м над ур.м. Состав: Malus sieversii $(80 \%)$ и M. niedzwetzkyana (20\%). Травяной покров состоит из злаков: Brachypodium pinnatum (доминант) и Elytrigia repens (доминант); из разнотравья: Pulmonaria mollis, Ranunculus repens, Anemone caerulea и Humulus lupulus (лиана). Проективное покрытие - 60 \%. Высота до 0,3 м. Жизненность по Сукачеву 1 балл. Размещение - диффузно и группами. Антропогенная трансформация - фоновая.

Участок 6. Злаково-яблоневое сообщество, 1359 м над ур.м. Состав: Malus sieversii (80 \%) и M. niedzwetzkyana (20\%). Травяной покров состоит из разнотравья: Dactylis glomerata (доминант) и Pulmonaria mollis. Проективное покрытие - 80 \%. Высота до 0,1 м. Жизненность по Сукачеву 1 балл. Размещение - диффузно. Антропогенная трансформация - фоновая.

Участок 11. Разнотравно-злаково-кустарниково-яблоневое сообщество, 1362 м над ур. м. Состав 10Я (14 экз.). Сомкнутость крон 0,5. Размер крон 4х6 м. Среднее расстояние между деревьями 3-5 м. Средний возраст 70-80 лет. Средняя высота 5-6 м. Средний диаметр 30 см. Бонитеты V, Va, Vб. Жизненность по Сукачеву 2 балла. Возобновление удовлетворительное (10 экз.). Подлесок состоит из Rosa platyacantha (доминант), Cerasus tianschanica, Spiraea hypericifolia, Juniperus sibirica. Растения плодоносят. Высота до 2 м. Размещение - группами.

Травяной покров состоит из разнотравья: Bromus squarrosus (доминант), Carex turkestanica, Sedum hybridum, Tulipa kolpakowskiana (краснокнижный вид), Artemisia rutifolia, Alyssum turkestanicum var. desertorum, Ferula sp., Ziziphora clinopodioides, Centaurea ruthenica u Potentilla sp. Проективное покрытие $-50 \%$. Задернованность - 5-10\%. Высота до 1 м. Жизненность по Сукачеву 1 балл. Размещение - пятнами и группами. Преобладают виды из Rosaceae (5 видов) и Asteraceae (2). Антропогенная трансформация - средняя. 
Участок 16. Разнотравно-злаково-кустарниково-яблоневое сообщество с боярышником, 1488 м над ур.м. Состав 9Я1Б: Malus sieversii (13 экз.), Crataegus songarica. Сомкнутость крон 0,8. Размер крон 5 х 7 м. Среднее расстояние между деревьями 3-5 м. Средний возраст 40-50 лет. Средняя высота 8 м. Средний диаметр 30 см. Полнота 0,5. Густота 30-50\%. Состояние удовлетворительное. Жизненность по Сукачеву 3 балла. Жизненность по Крафту I балл. Размещение - группами. В подлеске растет Rosa alberti (плодоносит).

Травяной покров состоит из разнотравья: Elytrigia repens (доминант), Poa pratensis (доминант), Silybum marianum (доминант), Euphorbia lamprocarpa, Ferula sp., Origanum vulgare, Convolvulus arvensis (цветет), Urtica dioica, Geranium pretense (цветет), Rumex confertus, Lappula squarrosa (цветет). Злаки в фазе семеношения. Проективное покрытие $-80 \%$. Задернованность $-30 \%$. Высота до 2 м. Жизненность по Сукачеву 1 балл. Размещение - группами и диффузно. Преобладают виды из Rosaceae (3 вида) и Роасеае (2). Антропогенная трансформация - средняя.

Участок 1. Злаково-разнотравно-боярышниково-яблоневое сообщество, 1489 м над ур. м. Состав 6Я5Б: Malus sieversii и Crataegus almaatensis. В подлеске - Ribes meyeri и Rubus idaeus. Начало цветения. Размещение - группами.

Травяной покров состоит из разнотравья: Dactylis glomerata (доминант), Pulmonaria mollis (доминант), Corydalis ledebouriana, Aquilegia vitalii (краснокнижный вид), Taraxacum officinale, Fragaria viridis, Artemisia absinthium, Gagea sp., Plantago major, Trifolium pratense, Urtica dioica, Ranunculus repens, Mentha asiatica, Viola altaica, Aconitum sp. Проективное покрытие - 70 \%. Задернованность - 5 \%. Высота до 0,25 м. Жизненность по Сукачеву 1 балл. Размещение - диффузно и группами. Антропогенная трансформация - фоновая.

Участок 5. Разнотравно-злаково-яблонево-еловое сообщество, 1495 м над ур.м. Состав: Picea schrenkiana и Malus sieversii. В подлеске-Rubus idaeus.

Травяной покров состоит из разнотравья: Dactylis glomerata (доминант), Paeonia anomala (краснокнижный вид), Achillea sp., Allium sp., Hedysarum neglectum и Sedum hybridum. Проективное покрытие $-90 \%$. Задернованность до $20 \%$. Высота травостоя до 0,3 м. Жизненность по Сукачеву 1 балл. Размещение - диффузно и группами. Антропогенная трансформация - фоновая.

Участок 17. Кустарниково-яблоневое сообщество, 1517 м над ур. м. Состав 10Я: Malus sieversii (7 экз.). Состав подлеска: Rosa alberti (плодоносит), Spiraea hypericifolia, Lonicera microphylla (плодоносит). Сомкнутость крон 0,8. Размер крон $5 \times 5$ м. Среднее расстояние между деревьями 3-5 м. Средний возраст 40-50 лет. Средняя высота 12 м. Средний диаметр 35 см. Густота до 50 \%. Состояние удовлетворительное. Жизненность по Сукачеву 3 балла. Жизненность по Крафту II балла. Возобновление яблони неудовлетворительное (5 экз.). Состояние удовлетворительное. Размещение - пятнами и группами.

Травяной покров состоит из разнотравья: Bromus squarrosus, Erigeron sp., Achillea millefolium, Allium atrosanguineum, Sedum hybridum, Althaea officinalis, Euphorbia lamprocarpa и Ferula sp. Проективное покрытие - 80 \%. Высота до 1 м. Размещение - группами и диффузно. Преобладают виды из Rosaceae (3 вида) и Asteraceae (2). Антропогенная трансформация - фоновая.

Заключение. Большая часть - 13 сообществ- относится к степному поясу (800-1400 м над ур. м.), образуя разнотравно-злаково-яблоневое (8 участок), злаково-разнотравно-тополево-яблоневое (2), злаково-разнотравно-кустарниково-боярышниково-осиново-яблоневое (12), боярышниково-яблоневое $(15)$, боярышниково-осиново-кленово-яблоневое $(13,14)$, злаково-кустарниково-яблоневое $(9)$, рябчиково-злаково-яблоневое с жимолостью (3), разнотравно-злаково-яблонево-еловое (4), разнотравно-шиповниково-яблоневое (10), злаково-яблоневое $(6,7)$, разнотравно-злаково-кустарниково-яблоневое (11) растительные сообщества.

В составе лесов из Malus sieversii произрастают древостои Malus niedzwetzkyana, Crataegus songarica, Acer semenovii, Populus tremula, Populus nigra и Picea schrenkiana. Подлесок состоит из ку- 
старников Berberis sphaerocarpa, Cerasus tianschanica, Rubus caesius, Lonicera microphylla, Rhamnus cathartica, Rubus idaeus, Juniperus sibirica, Prunus stepposa, Spiraea hypericifolia, Padus avium, Rosa alberti и R. platyacantha.

Количество деревьев- 4-20 экз. Сомкнутость крон -0,5-0,8. Размер крон -4 х 7 м. Среднее расстояние между деревьями $-2-5$ м. Средний возраст $-15-80$ лет. Средняя высота $-3-12$ м. Средний диаметр -10-41 см. Бонитеты V, Va, Vб. Полнота до 0,8. Густота -20-50 \%. Возобновление Malus sieversii от неудовлетворительного (1 экз.) до хорошего (75 экз.). Жизненность по Сукачеву $-2-3$ балла. Жизненность по Крафту -II балла. Состояние удовлетворительное. Размещение - пятнами, группами и диффузно.

Травяной покров состоит из разнотравья: Pulmonaria mollis, Euphorbia lamprocarpa, Urtica dioica (доминант), Aconitum (доминант), Arctium lappa, Ranunculus repens, Ligularia sp., Anemone caerulea, Origanum vulgare, Solidago virgaurea, Hypericum scabrum, Berteroa incana, Hedysarum neglectum, Sedum hybridum, Filipendula ulmaria, Goniolimon sp., Ferula sp., Impatiens noli-tangere, Corydalis ledebouriana, Chelidonium majus, Dryopteris filix-mas, Berberis sphaerocarpa, Conium maculatum, Heracleum dissectum, Alyssum turkestanicum var. desertorum, Centaurea pseudosquarrosa, C. ruthenica, Thalictrum minus, Bupleurum exaltatum, Convolvulus arvensis, Persicaria, Inula britannica, Hypericum perforatum, Ziziphora clinopodioides, Chamaenerion angustifolium, Senecio sp., Potentilla sp., Alopecurus pratensis, Arctium leiospermum, Taraxacum officinale, Artemisia vulgaris, A. rutifolia, A. dracunculus, Fritillaria pallidiflora (краснокнижный вид, доминант), Glycyrrhiza uralensis, Tulipa kolpakowskiana (краснокнижный вид), Chondrilla juncea, Salvia deserta, Humulus lupulus (лиана). Состав злакоцветных: Dactylis glomerata (доминант), Brachypodium pinnatum (доминант), Elytrigia repens (доминант), Bromus squarrosus (доминант), B. japonicus, Poa pratensis и P. bulbosa (доминанты), Carex turkestanica.

Проективное покрытие - 50-80\%. Задернованность - 10-60 \%. Жизненность по Сукачеву 1-2 балла. Размещение - группами и пятнами. Преобладают виды из Rosaceae, Asteraceae и Poaceae. Антропогенная трансформация от фоновой до средней, сильная единично.

Сомкнутые яблоневые леса приуроченые к поясу мелколиственных лесов (1400-1700 м) образуют следующие сообщества: разнотравно-злаково-кустарниково-яблоневое с боярышником (16 участок), злаково-разнотравно-боярышниково-яблоневое (1), разнотравно-злаково-яблонево-еловое (5) и кустарниково-яблоневое (17). В составе лесов из Malus sieversii произрастают древостои из Crataegus almaatensis, Crataegus songarica, Picea schrenkiana. Подлесок состоит из Rosa alberti (плодоносит), Ribes meyeri, Spiraea hypericifolia, Lonicera microphylla (плодоносит) и Rubus idaeus.

Количество яблонь 7-13 экз. Сомкнутость крон 0,8. Размер крон 5 х 7 м. Среднее расстояние между деревьями 3-5 м. Средний возраст 40-50 лет. Средняя высота 8-12 м. Средний диаметр 30-35 см. Полнота до 0,5. Густота 30-50 \%. Состояние удовлетворительное. Жизненность по Сукачеву 3 балла. Жизненность по Крафту I-II балла. Возобновление Malus sieversii удовлетворительное (5 экз.). Состояние удовлетворительное. Размещение - пятнами и группами.

Травяной покров состоит из разнотравья: Urtica dioica, Ferula sp., Sedum hybridum, Aquilegia vitalii, (краснокнижный вид), Convolvulus arvensis (цветет), Geranium pratense (цветет), Hedysarum neglectum, Lappula squarrosa (цветет), Ranunculus repens, Pulmonaria mollis (доминант), Paeonia anomala (краснокнижный вид), Allium atrosanguineum, Euphorbia lamprocarpa, Achillea millefolium, Aconitum, Althaea officinalis, Geranium pratense, Gagea sp., Origanum vulgare (цветет), Fragaria viridis, Trifolium pretense (цветет), Erigeron sp., Mentha asiatica, Taraxacum officinale, Plantago major, Artemisia absinthium, Silybum marianum (доминант), Viola altaica, Corydalis ledebouriana, Rumex confertus. Состав из злаков: Dactylis glomerata (доминант), Bromus squarrosus, Poa pratensis (доминант) и Elytrigia repens (доминант).

Проективное покрытие - 70-90 \%. Задернованность - 5-30\%. Жизненность по Сукачеву -1 балл. Преобладают виды из Rosaceae, Asteraceae и Роaceae. Антропогенная трансформация от фоновой до средней. Размещение - группами и диффузно.

Для видов, внесенных в Красную книгу Казахстана (2014), необходимо проводить мероприятия по сохранению и приумножению в природных условиях: Fritillaria pallidiflora, Tulipa kolpakowskiana, Aquilegia vitalii, Paeonia anomala. 
Больше часть яблоневых сообществ произрастает на склонах Тополевской $(1,13,14,15$ участки) и Лепсинской $(2,3,4,5,6,16,17)$ межгорных котловин, что согласуется с данными А. Д. Джангалиева (1977).

В древостоях из Malus sieversii часто встречается Malus niedzwetzkyana (3, 6 и 7 участки). Оба вида произрастают в Джунгарском и Илейском Алатау (Заилийский Алатау), что подтверждается гербарными сборами Л. Н. Грибанова в 1972 г., данными Н. П. Огарь (Peix et al., 2018), А. А. Иващенко и P.M. Турехановой (2015). Однако в научных справочных изданиях данный вид для Джунгарского и Заилийского Алатау не указан (Флора Казахстана, 1956-1966; Иллюстрированный определитель ..., 1969; Джангалиев, 1977; Голоскоков, 1984; Красная книга Казахстана, 2014). Рекомендуем в следующих изданиях этих книг указать этот вид для названных регионов.

Malus sieversii и Malus niedzwetzkyana занесены в Красную книгу Казахстана (2014), их численность имеет тенденцию к сокращению, виды находятся под угрозой исчезновения. Предлагаем для сохранения и восстановления яблоневых лесов контролировать и управлять факторами антропогенного воздействия, осуществлять регулярный мониторинг текущего состояния лесов, проводить мероприятия по их сохранению in-situ и ex-situ в специальных питомниках и ботанических садах.

\section{ЛИТЕРАТУРА}

Анучин Н. П. Лесная таксация. - Москва: Лесная промышленность, 1982. - 552 с.

Быков Б. А. Геоботанический словарь. - Алма-Ата: Наука., 1973. - 216 с.

Быков Б. А. Геоботаника. - Алма-Ата, 1978. - 288 с.

$\boldsymbol{B}$ олкова $\boldsymbol{E}$. $\boldsymbol{A}$. Растительный покров гор // Ботаническая география Казахстана и Средней Азии (в пределах пустынной зоны). - СПб, 2003. - С. 167-191.

Голоскоков В. П. Флора Джунгарского Алатау (конспект и анализ). - Алма-Ата: Наука, 1984. - 224 с.

Голуб В. Б. Использование геоботанических описаний в качестве коллекции образцов для классификации растительности // Растительность России. - СПб., 2011. - № 17-18. - С. 70-83.

Джсангалиев А. Д. Дикая яблоня Казахстана. - Алма-Ата: Наука, 1977. - 283 с.

Джсангалиев А. Д. К итогам 60-летних исследований яблоневых лесов Заилийского и Джунгарского Алатау // Растительный мир и его охрана: Труды Междунар. научн. конф., посвящ. 75-летию Института ботаники и фитоинтродукции (12-14 сентября, 2007 г.). - Алма-Ата, 2007. - С. 208-212.

Иващенко А. А., Туреханова Р. М. Труды Иле-Алатауского национального парка. - Астана: Жасыл Орда, 2015. - Вып. 1. - $290 \mathrm{c}$.

Иллюстрированный определитель растений Казахстана. - Алма-Ата: Наука, 1969. - Т. 1. - 644 с.; 1972. T. $2 .-571 \mathrm{c}$.

Касенова Г., Кентбаева Б. А. Состояние лесного фонда Жонгар-Алатауского ГНПП // Ізденістер, нәтижелер Исследования, результаты. - Алматы, 2017. - № 2 (74). - С. 210-214.

Красная книга Казахстана. Т.2: Растения - Астана: AprPrintXX, 2014. - 452 c.

Мичурин И. В. Сочинения в 4-х томах. - М.: ОГИЗ: СЕЛЬХОЗГИЗ, 1948. - 341 с.

OCT 56-69-83. Площади пробные лесоустроительные. Методы закладки / В. И. Сухих, Ю. А. Кукуев, А. Н. Шульгин, В. Д. Сенько. Центральное бюро научно-технической информации Гослесхоза СССР. - Москва, 1984. $-80 \mathrm{c}$.

Рачковская E. И., Садвокасов Р. Е., Темирбеков С. Использование методов дистанционного зондирования для оценки опустынивания пастбищ предгорных пустынь // Трансформация природных экосистем и их компонентов при опустынивании. Научный сборник. - Алматы: Наурзум (НПО), Экологический исследовательский центр ЭНВИРС, 1999. - С. 76-80.

Рачковская Е. И., Сафронова И. Н., Волкова Е. А. Принципы и основные единицы районирования // Ботаническая география Казахстана и Средней Азии (в пределах пустынной зоны). - СПб, 2003. - С. 192-195.

Ролдугин И. И., Мальцев С. Н. Древесные растения. Справочник. - Алматы, 2011. - 231 с.

Сукачев В. Н., Зонн С. В. Методические указания к изучению типов леса. - М., 1961. - 142 с.

Флора Казахстана / под ред. Н. В. Павлова. - Алма-Ата: Наука, 1956-1966. - Т. І-ІХ.

Черепанов С. К. 1995. Сосудистые растения России и сопредельных государств (в пределах бывшего СССР). - СПб. $-990 \mathrm{c}$.

Юнатов $\boldsymbol{A}$. $\boldsymbol{A}$. Типы и содержание геоботанических исследований. Выбор пробных площадей и заложение экологических профилей // Полевая геоботаника. - М.-Л., 1964. - Т. 3. - С. 9-135.

Реix С., Огарь Н. П., Галимов Т., Натбаев Ж. Malus sieversii - Malus sieversii (Ledeb.) M. (Roem). - Алматы: Полидей, 2018. - 200 с. (русский, английский). 